Research Article

\title{
Experimental Study on Stress Evolution and Microseismic Signals under Vibration Conditions of Coal during Excavation and Subsequent Waiting Time
}

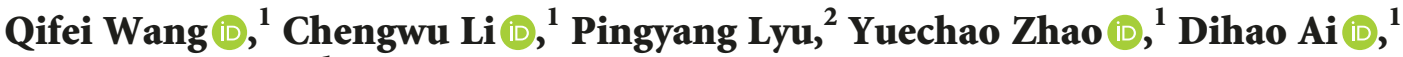 \\ and Beijing Xie $\mathbb{C}^{1}$ \\ ${ }^{1}$ College of Emergency Management and Safety Engineering, China University of Mining and Technology (Beijing), \\ Beijing 100083, China \\ ${ }^{2}$ Institute of Remote Sensing and Geographic Information System, Peking University, Beijing 100871, China
}

Correspondence should be addressed to Chengwu Li; lcw@cumtb.edu.cn and Beijing Xie; bjxie1984@cumtb.edu.cn

Received 2 April 2019; Revised 8 June 2019; Accepted 17 June 2019; Published 2 July 2019

Academic Editor: Chao Tao

Copyright (C) 2019 Qifei Wang et al. This is an open access article distributed under the Creative Commons Attribution License, which permits unrestricted use, distribution, and reproduction in any medium, provided the original work is properly cited.

An experiment designed to simulate coal during excavation was conducted. Microseismic signals of coal under vibration conditions during excavation and subsequent waiting time of the coal roadway at different excavation speeds were collected and analyzed. During the excavation and subsequent waiting time, the stress in coal is redistributed, and the concentrated stress is gradually transferred to the deeper section of the coal seam. The Hilbert-Huang transform (HHT) is used to effectively denoise the collected signals. According to the noise-reduced signal, the amplitude and pulse number of the microseismic signals emitted during the excavation process are much larger than those of the waiting time process. During excavation, the energy and event numbers of microseismic signals increase first and then decrease as the excavation speed increases. The faster the excavation speed, the more the energy, and the higher the event numbers of the microseismic signals released during the subsequent waiting time. When the excavation speed is faster, more elastic potential accumulates in the coal seam and the concentration stress is greater. As the concentrated stress moves forward in time without excavation, more coal seams fail, and more microseismic signals are released. The microseismic signal and the stress evolution law can provide a reasonable explanation for the forward movement of the concentrated stress and coal failure during roadway excavation.

\section{Introduction}

In underground mine mining, rock and coal are subjected to tremendous overlying strata pressure and tectonic stress. The original stress balance state of the mine is disrupted during the mining operation, which may trigger the transfer of stress and the concentration of local stress. This process is often accompanied by the rupture of coal, which can cause release of microseismic and acoustic emission signals. The main causes of microseismic events are slip and dislocation of existing cracks in mines under the action of tectonic and mining stress [1]. Real-time monitoring of coal-rock microseismic signals has become an important means to predict coal-rock dynamic disasters in underground mining [2].
During the past 20 years, microseismic monitoring has been widely used in major mineral-producing regions and countries, such as Europe, South Africa, North America, Canada, and China [3-6]. Since the 1970s, the United States has used microseismic monitoring in mines to ensure the safety of underground personnel and developed supporting software and hardware for this purpose [7]. As the technology has matured, the microseismic technique has become the fundamental monitoring approach for mine safety and ground control. Luo et al. studied the roof fracture process and stability using the microseismic method [8]. Mansurov analyzed the microseismic data gathered by North Ural Bauxite Mines. Mansurov demonstrated that the microseismic signal is a highly efficient and accurate predictor of strong impact ground pressure [9]. Wang et al. conducted 
the 80-day monitoring at the Qixing Coal Mine through a high-precision microseismic monitoring system [10]. Zhang et al. studied the correlation length of mine microseismic signals at different spatial scales with a single-link cluster method and analyzed its mechanism [11].

With the advancement in signal analysis and processing technology, experts and scholars have formed more in-depth research on microseismic signals in mines based on the analysis of the relationship between the number of microseismic signal events and coal-rock dynamic disasters. Li et al. discussed weak signal detection using multiscale morphology in microseismic monitoring which improves detection of more wave modes such as $\mathrm{P}$ and $\mathrm{S}$ waves, for better performance [12]. CAO et al. found that the average $\mathrm{P}$-wave velocity, the average maximum amplitude, and the main frequency of microseismic signals in the Australia Southern Coal Mine decreased significantly with an increase in goaf and roof rupture [13]. This outcome provides a technical basis for the microseismic signal to be used to monitor the stability of roadway surrounding rock. Ghosh and Sivakumar et al. monitored and analyzed the sequence of microseismic events in coal mines in southeastern India and studied the relationship between microseismic activity rate, potential energy, viscosity rate, seismic moment, energy index, apparent volume, potential energy, and roof fall event [14]. Phillips et al. [15], Rowe et al. [16], and Gibowicz et al. [17] conducted in-depth research on the source of microseismic signals in the mine, the location of the rupture zone, and high-precision signal acquisition methods. Lu et al. analyzed the microseismic signals of mines with a band-stop filter and studied the characteristics of low-frequency precursor signals under coal bursting failure. Studies have shown that the rock-burst intensity and signal intensity display a significant positive correlation [18]. Sikora used a variety of mathematical methods to study the relationship between coal mine microseismic signals and mine risk. In the study, the classification results achieved using decisiontree induction and fuzzy neural networks were more reasonable than those achieved using rule-based classification [19]. Based on a study of the characteristics of mine microseismic signals, Vallejos and Mckinnon proposed a neural network model to classify the sources of microseismic events [20]. Jiang et al. used velocity model optimization for surface microseismic monitoring via amplitude stacking to enhance the signal-to-noise ratio in the coal-bed gas reservoir in Western China [21]. To investigate the generation mechanism of microseismic signals, most scholars use numerical simulation. Based on the traditional stress and coal rock failure model, numerical simulation has revealed that the concentrated stress zone and the damage zone of the mining roadway are the areas in which microseismic events are concentrated [22].

In summary, the study of mine microseismic signals typically focuses on the characteristics of on-site microseismic signals and the mechanism analysis is based on numerical simulation. Laboratory research usually focuses on the characteristics of microseismic signals in the process of coal and rock loading and failure. The experimental results primarily reflect the mechanical characteristics of coal and rock samples. There are few studies on the characteristics and energy trends of microseismic signals during coal seam excavation that employ similar simulation experiments. In this paper, through an original coal tunnel driving simulation experiment system, the microseismic signals at different excavation speeds are synchronously monitored, and the characteristics and energy trends of the signals during simulated coal seam excavation are studied. This approach and its results are of substantial value to the theory of applied research on early warning of coal-rock dynamic disasters.

\section{Experimental System for Coal Roadway Excavation}

2.1. Experimental System. To study the characteristics of microseismic signals during roadway excavation, the author designed an experiment that simulated the coal body under different excavation speeds and collected the microseismic signals that occurred during the experiment. The structure of the experimental system is shown in Figure 1. The system primarily consists of three parts: stress loading, excavation equipment, and the signal acquisition system. The coal roadway excavation simulation experiment system is shown in Figure 2.

In similar simulation tests of coal roadway excavation, the method of loading steel plates with jacks is typically used to simulate the stress state of coal seams. With this stress loading method, the stress at the pressure head of the jack is large, the stress at the edge is small, and the stress loading is not uniform. In this experiment, the hydration expansion reaction of the expansion agent in the closed experimental tank is used as the stress source. The characteristics of the stress evolution law and microseismic signals in the process of coal seam excavation are studied by drilling the loaded coal body.

The production process of the pressed coal body used in the experiment is as follows. (1) The pulverized coal and the coal tar are mixed uniformly. (2) The mixture is poured into a circular cavity with an inner diameter of $128 \mathrm{~mm}$, and a cylindrical steel pipe with a diameter of $28 \mathrm{~mm}$ is placed in the cavity. (3) The pulverized coal in the cavity is compacted with servo press. (4) The steel pipe is extracted from the coal body to form a hole. (5) The prepared expansion agent is filled in the remaining cylindrical hole, and the two ends are blocked. The volume expansion of the expansion agent after the hydration reaction causes the cavity to elastically deform and apply uniform stress to the internal coal body, which is used to simulate the loaded coal body in front of the roadway. During the experiment, SF1500 MEMS capacitive accelerometer was used to synchronously collect the microseismic signals. The microseismic signals that occurred during the simulated excavation process were collected by a HIOKI8860-50 storage recorder. The frequency of the microseismic signal is generally below $1000 \mathrm{~Hz}$. According to the Nyquist sampling theorem, when the sampling frequency is greater than $2000 \mathrm{~Hz}$, the acquired digital signal can completely retain the information in the original microseismic signal. In the 


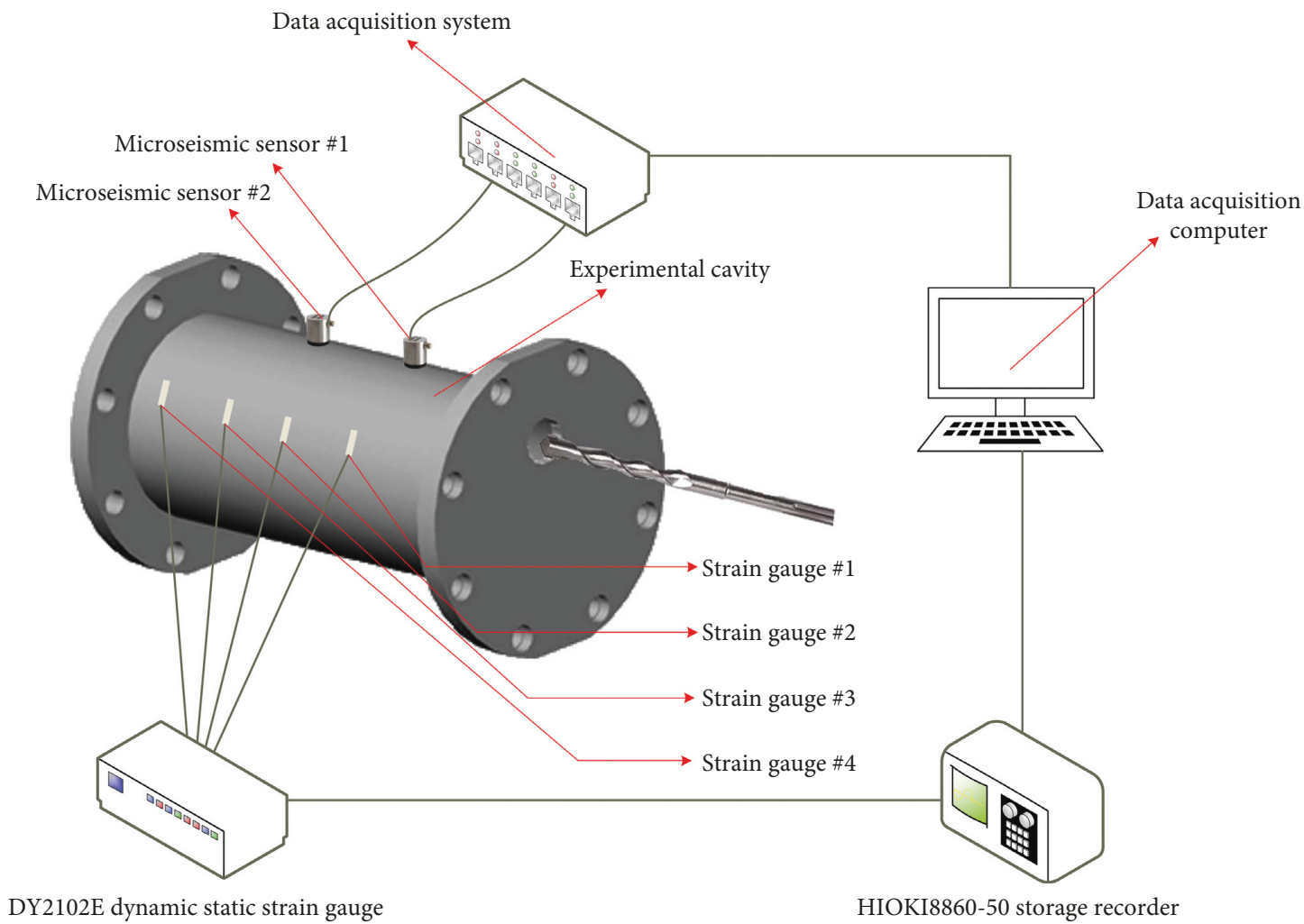

Figure 1: Experimental system.

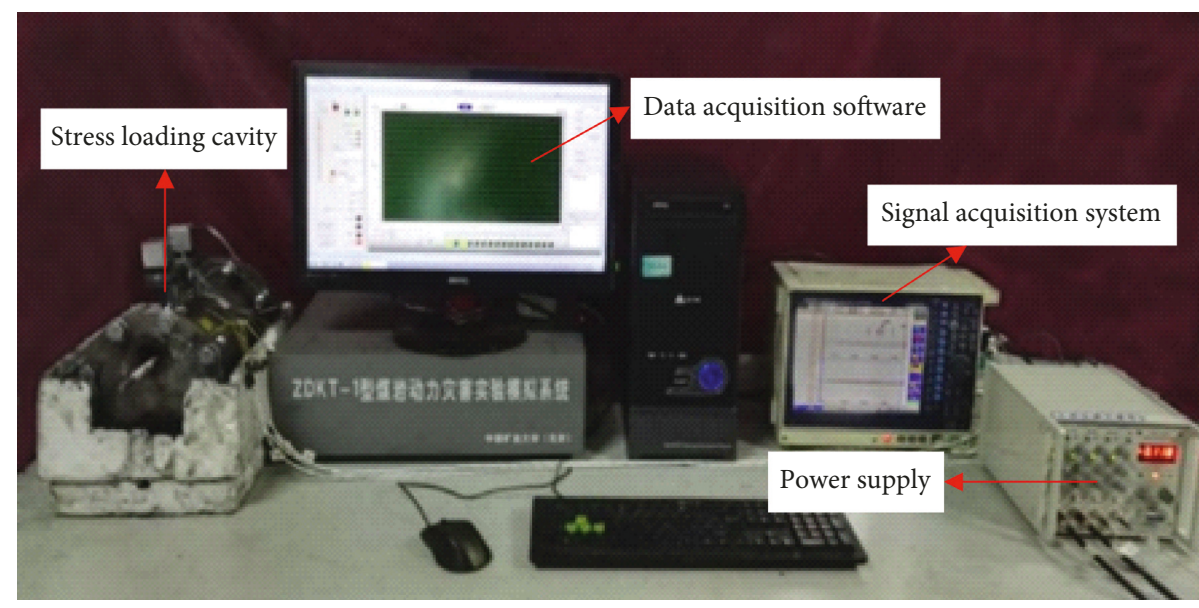

FIGURE 2: Coal roadway excavation simulation experiment system.

experiment, the sampling frequency of the microseismic signal was set to $10240 \mathrm{~Hz}$. The strain sensor was a DY2102E dynamic static strain gauge, and the signal acquisition system was a MEMORY HiCOROER 8860-50 storage recorder manufactured by HIOKI, Japan.

2.2. Determination of Similar Experimental Parameters. The parameters of the experimental model are determined according to the design principles of similar simulation experiments. The similar experiments were required to satisfy single-value similar conditions such as geometric conditions, physical conditions, boundary conditions, and initial conditions.

The purpose of this experiment is to qualitatively analyze the influence of excavation speed on the damage area in front of the roadway. Therefore, to avoid the boundary effect, the determination of the geometric similarity ratio must meet the requirements of the roadway excavation. Generally, the geometric similarity ratio of qualitative simulation experiments is 100-200. In this experiment, the determined geometric similarity ratio is $\alpha_{L}=150$. Since the diameter of the on-site prototype roadway is $3 \mathrm{~m}$, the diameter of the model roadway is $3 \mathrm{~m} / 150=20 \mathrm{~mm}$. 
The material used in this simulation experiment is briquette, which is an approximately homogeneous material made by evenly mixing and compacting coal tar and pulverized. The bulk density of the material is close to that of the raw coal. Thus, the similarity ratio of bulk density $\alpha_{\gamma}$ is approximately 1 .

The coal roadway excavation process conventionally proceeds over three work shifts a day, whereby the overhaul shift does not perform excavation work for eight hours. During the two excavation shifts, part of the time is used for excavation, while the remaining time is used to support site cleaning and other operations. The excavation period represents approximately $15 \%-20 \%$ of the excavation shift, approximately 96 minutes. Time similarity ratio $\alpha_{t}$ can be calculated according to an acceleration similarity criterion: $\alpha_{t}=\sqrt{\alpha_{L}}=\sqrt{150} \approx 12$. Therefore, the duration of a single excavation operation in the simulation experiment is $96 \mathrm{~min} / 12=8$ minutes.

When the depth of the simulated coal seam is $400 \mathrm{~m}$, the in-situ stress can reach approximately 5.6 MPa. According to the stress-strain relationship, the stress similarity ratio can be calculated: $\alpha_{\sigma}=\alpha_{L} \alpha_{\gamma}=150$. Therefore, the stress around the experimental model roadway is not less than $5.6 \mathrm{MPa} /$ $150=37 \mathrm{KPa}$.

2.3. Experimental Program. The roadway excavation simulation test can be used to study the influence of excavation speed on the coal failure in front of the working face. To order to conform to the actual operation process, the excavation-waiting process was repeated during the experiment. We performed a simulated excavation experiment at three different excavation speeds: $v_{1}=1.875 \mathrm{~mm} / \mathrm{min}$, $v_{2}=3.125 \mathrm{~mm} / \mathrm{min}$, and $v_{3}=4.375 \mathrm{~mm} / \mathrm{min}$.

The simulated excavation experiment process is divided into three stages: (1) $15 \mathrm{~mm}$ of coal is excavated with speed $v_{1}$ and then allowed to wait for $32 \mathrm{~min}$, followed by excavating another $15 \mathrm{~mm}$ and waiting for $40 \mathrm{~min}$; (2) $25 \mathrm{~mm}$ of coal is excavated with speed $v_{2}$ and then allowed to wait for $32 \mathrm{~min}$, followed by excavating another $25 \mathrm{~mm}$ and waiting for $40 \mathrm{~min}$; (3) $35 \mathrm{~mm}$ of coal is excavated with speed $v_{3}$ and then allowed to wait for $35 \mathrm{~min}$, followed by excavating another $35 \mathrm{~mm}$ and waiting for $32 \mathrm{~min}$. The schematic diagram of the excavation scheme is shown as Figure 3.

As shown in Figure 3, the simulation excavation test can be divided into four stages. The first stage is to open the excavation inlet reserved on the cavity, which is similar to the process of uncovering the coal wall at the coal mine site. The second, third, and fourth stages simulate the excavation process under different excavation speeds. Two excavation simulations were performed at each stage. The excavation footage, time, and speed of each stage are shown in Table 1.

\section{Experimental Results and Signal Denoising}

3.1. Stress Change during the Excavation and Waiting Time. The test chamber is a steel cylindrical tank, and the tank provides stress to the inner coal seam based on the reaction of the expansion agent. The stress at each tank position represents the stress state of the coal seam at that position. The reserved tunneling holes must be opened before the tunneling process is simulated. A period of time after opening the tunneling hole and the stress of the coal seam at points \#1, \#2, \#3, and \#4 are measured. The stress evolution is shown in Figure 4.

After the tunneling hole of the roadway is opened, the stress of the coal seam at point $1 \#(50 \mathrm{~mm}$ from the initial heading face) displays a downward trend (Figure 4). The stress of the coal seam at point $2 \#(100 \mathrm{~mm}$ from the initial heading face) and point $3 \#$ (150 $\mathrm{mm}$ from the initial heading face) increases steadily, and the stress of the coal seam at point 2\# increases more rapidly (Figure 4 ). The stress of the coal seam at point $4 \#$ (200 $\mathrm{mm}$ from the initial heading face) scarcely changes (Figure 4). Therefore, in this stage, point 1\# is located in the reduced stress zone, point $2 \#$ and point $3 \#$ are located in the increased stress zone, and the point $4 \#$ is located in the stabled stress zone. The stress decreases near the coal wall, and the stress concentration in the middle of the experimental coal during uncovering of the coal wall is obvious.

Figures 5 and 6 show the stress evolution during excavation and waiting time in the second stage, respectively. During coal excavation, the stress at point $\# 1$ near the heading face is decreased, and the stress at the farther point \#2 exhibits an upward trend (Figure 5). This outcome indicates that the concentrated stress of the coal seam is shifting during excavation. However, due to the short time of the simulated excavation, the change in coal seam stress is small. The stress at points \#3 and \#4 far from the head is basically unchanged (Figure 5 ).

As shown in Figure 6, the stress of the coal seam continues to change during the waiting time. The stress at point \#1 is continuously decreasing. The stress of the coal seam in a certain range ahead of the heading face increases, whereby the stress at point \#2 increases obviously, and the stress at the point \#3 increases slightly in the fluctuation. The deep stress of the coal seam (point \#4) is little changed. During the waiting time and the excavation process, the concentrated stress is transferred to the deep part of the coal seam.

In order to describe more the changes of the stress during the experiment intuitively, we subtract the initial value from the stress of all points. The evolution law of stress at each point during the whole experiment is shown in Figure 7. During the excavation and subsequent waiting time of the simulation experiment, the stress of point \#1 showed a continuous downward trend with slight fluctuations in the medium term. During the first three tunneling operations, the stress of point \#2 increased significantly. After the fourth excavation (the second excavation in the second stage), the stress of point \#2 began to drop significantly. However, the stresses at points \#3 and \#4 remained almost unchanged during the early stages of the experiment and decreased significantly in the third stage. As a result, significant pressure relief has occurred in the coal seam that have been excavated, significant stress concentrations have occurred in front of the work face, and the concentrated stresses have shifted to the deep coal as the excavation work continues. 


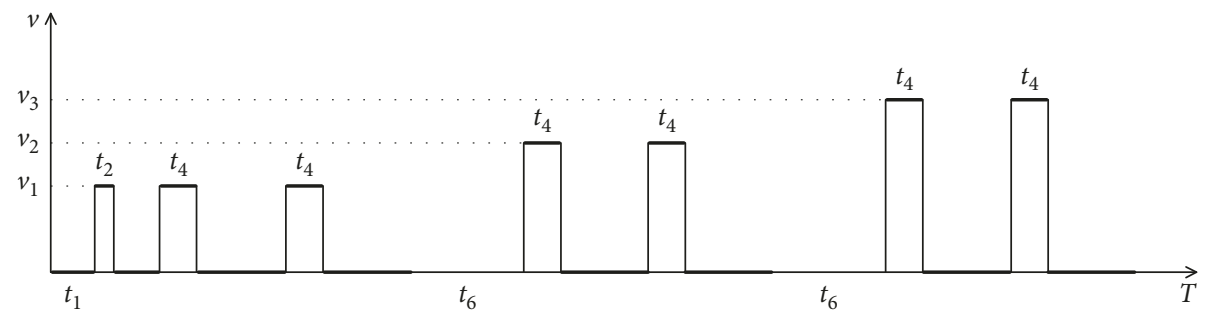

Figure 3: Schematic diagram of the excavation scheme. Note. $v_{1}, v_{2}$, and $v_{3}$ are the excavation speeds; $t_{1}$ is the time before excavation; $t_{2}$ is the time of each excavation; $t_{3}$ is the waiting time of the excavation shift; and $t_{4}$ is the waiting time of the overhaul shift.

TABLE 1: Excavation load.

\begin{tabular}{|c|c|c|c|c|c|}
\hline \multicolumn{2}{|c|}{ Stage and process } & \multirow{2}{*}{$\begin{array}{c}\text { Excavation footage }(\mathrm{mm}) \\
10\end{array}$} & \multirow{2}{*}{$\begin{array}{c}\text { Footage summed (mm) } \\
10\end{array}$} & \multirow{2}{*}{$\begin{array}{c}\text { Excavation time }(\mathrm{min}) \\
-\end{array}$} & \multirow{2}{*}{$\begin{array}{c}\text { Excavation speed } \\
(\mathrm{mm} / \mathrm{min})\end{array}$} \\
\hline First stage & & & & & \\
\hline \multirow{2}{*}{ Second stage } & First excavation & 15 & 25 & 8 & 1.875 \\
\hline & Second excavation & 15 & 40 & 8 & 1.875 \\
\hline \multirow{2}{*}{ Third stage } & First excavation & 25 & 65 & 8 & 3.125 \\
\hline & Second excavation & 25 & 90 & 8 & 3.125 \\
\hline \multirow{2}{*}{ Fourth stage } & First excavation & 35 & 125 & 8 & 4.375 \\
\hline & Second excavation & 35 & 160 & 8 & 4.375 \\
\hline
\end{tabular}

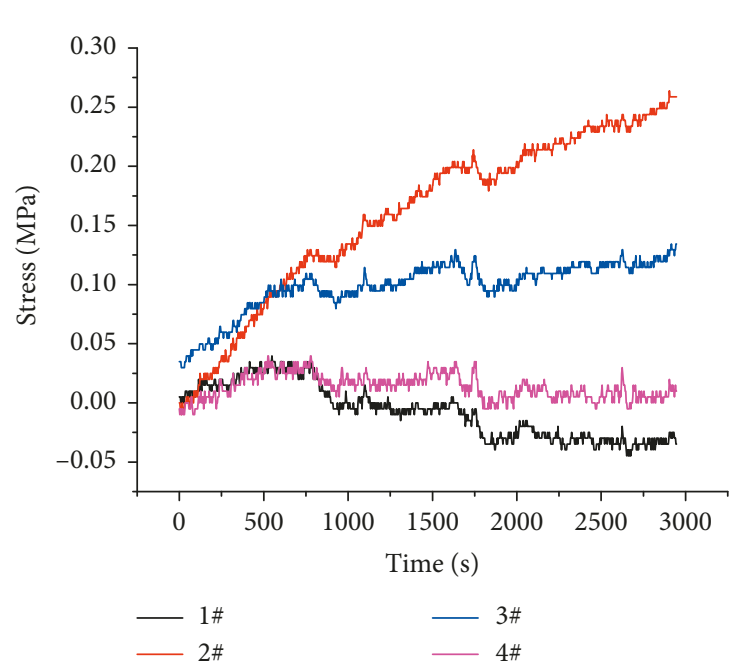

(a)

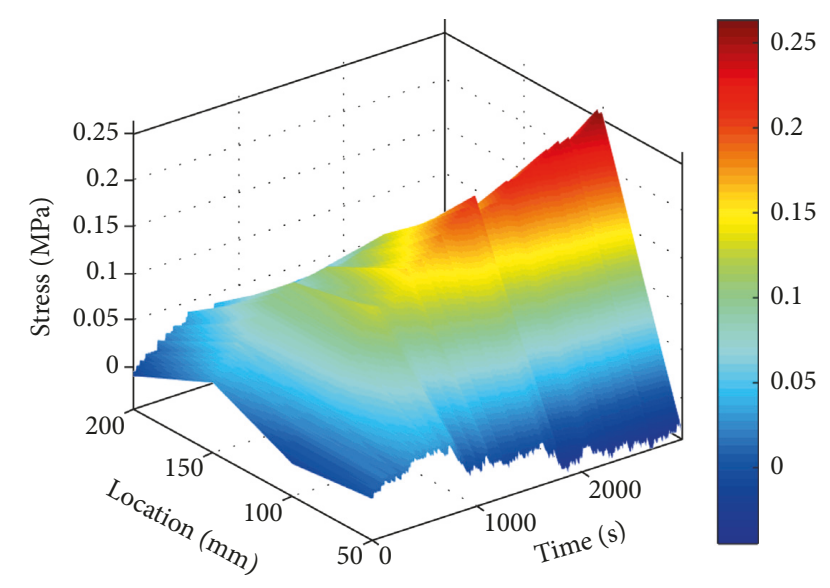

(b)

FIGURE 4: Stress evolution after opening the tunneling hole: (a) stress-time curve of 4 measuring points; (b) diagram of stress distribution in different locations over time.

3.2. Microseismic Signal Acquisition and Denoising. The microseismic signals released during the fracture process of coal mine rock and coal can be collected by the microseismic monitoring system. However, the collected original signal is generally one in which a noise signal is superimposed on the genuine microseismic signal. The noise signal typically includes stable background noise and a random transient interference signal. Analysis and processing of the original microseismic signals to identify the anomalous signals forms the basis for studying the early warning of coal and rock dynamic disasters based on microseismic monitoring. Mine microseismic signal waveforms primarily display the following characteristics. (1) The abnormal microseismic signal is a typical nonstationary signal, which contains information on coal and rock damage; (2) the microseismic event is typically a short-term pulse signal, and abnormal signal recognition is highly difficult; and (3) many different operations are involved in underground coal mining, which results in a variety of noises in the collected microseismic signals, and the signal-to-noise ratio is relatively low. To extract useful information from the recorded microseismic signals, the time-frequency analysis method represented by 


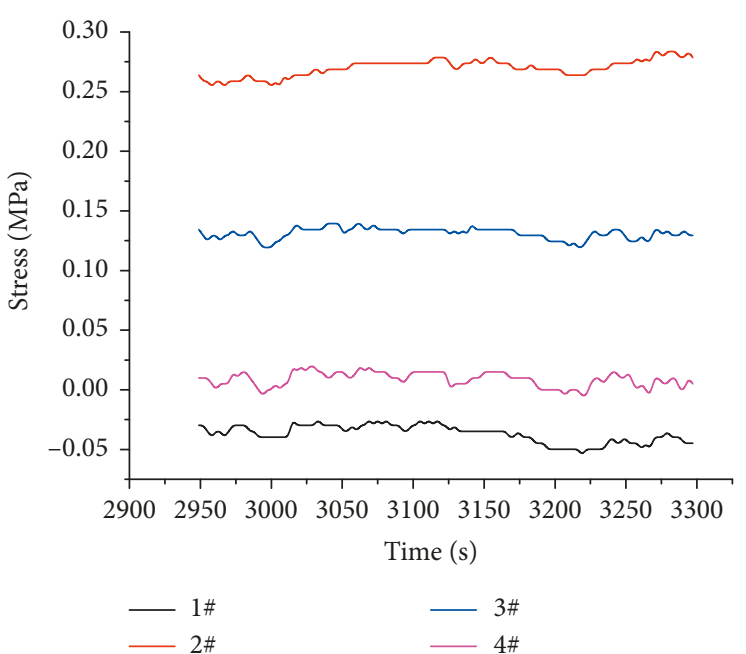

(a)

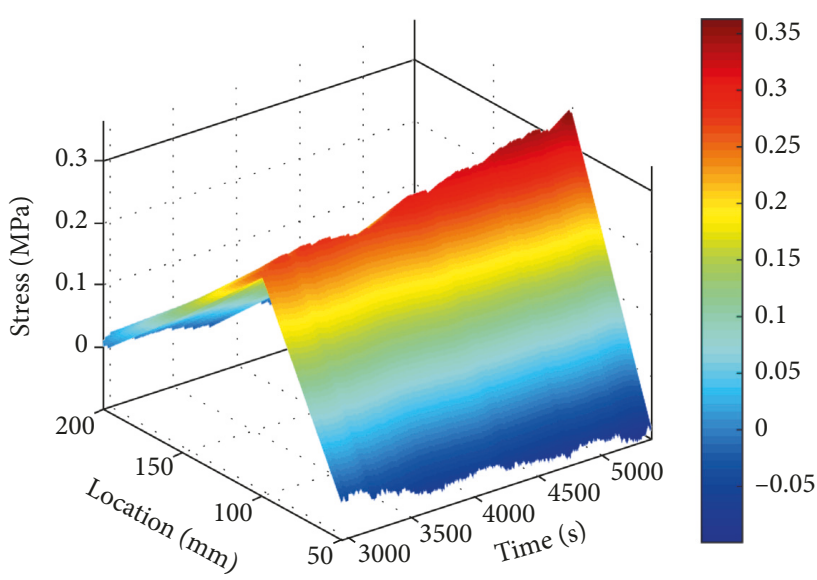

(b)

FiguRE 5: Stress evolution during the first excavation in the second stage: (a) the stress-time curve of 4 measuring points; (b) diagram of stress distribution at different locations over time.

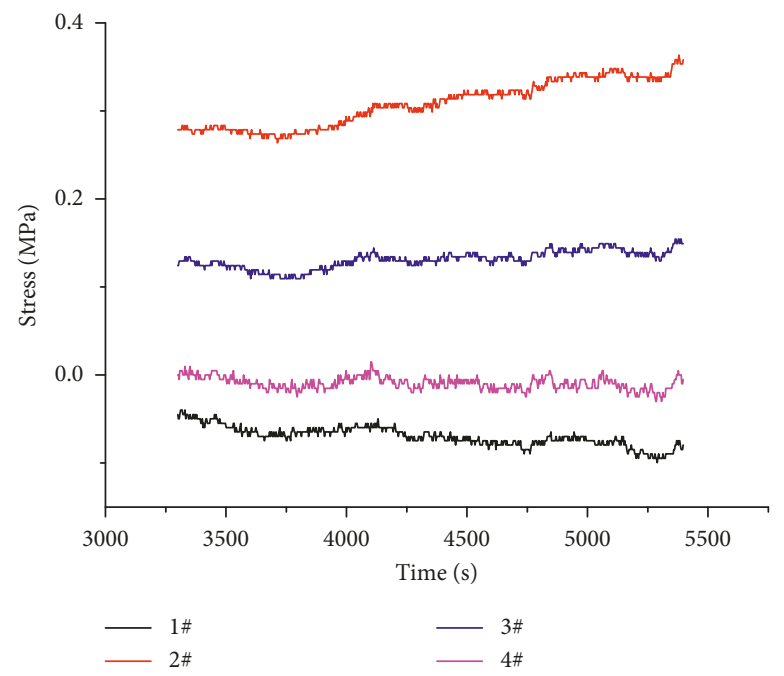

(a)

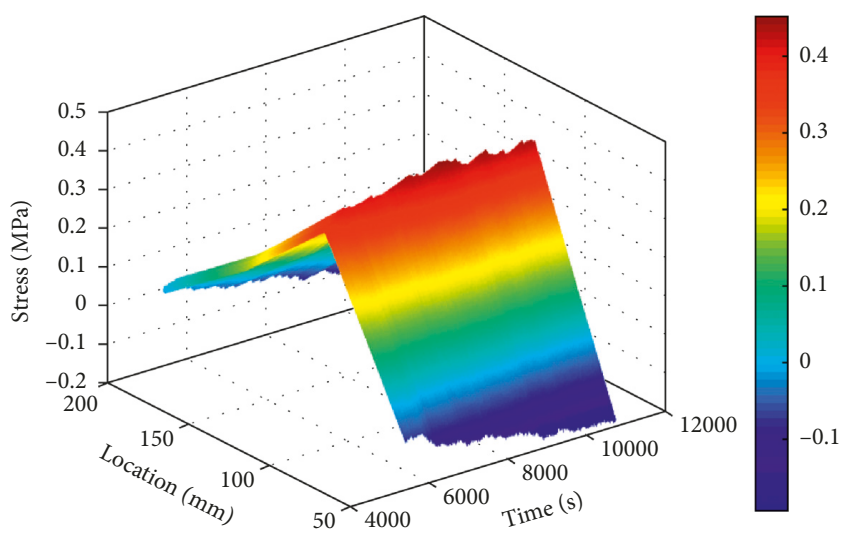

(b)

Figure 6: Stress evolution in the waiting time of the second stage: (a) stress-time curve of 4 measuring points; (b) diagram of stress distribution at different locations over time.

the Fourier transform has been widely used [23-26]. The Fourier transform is useful in analyzing the spectral characteristics of stationary signals at fixed time scales. However, it has substantial limitations in addressing nonstationary signals [27]. Wavelet analysis is a nonstationary signal processing method based on wavelet decomposition and widely used to denoise signals. Wavelet noise reduction is performed by setting a certain threshold to process various wavelet components obtained by wavelet decomposition and by reconstructing components containing useful signals to complete signal processing [28-30]. Wavelet functions, also known as wavelet bases, are characterized by orthogonality and symmetry. Wavelet analysis has been demonstrated to be a useful means to address nonstationary signals, such as earthquakes and electromagnetic radiation [31, 32]. However, the characteristic of wavelet finite length will cause the leakage of signals energy, and the analysis results are substantially influenced by the choice of wavelet basis functions [33].

In recent years, a new method termed the HilbertHuang transform (HHT) has been used increasing widely because of its powerful processing power for nonlinear nonstationary signals. The HHT consists of empirical mode decomposition (EMD) and the Hilbert transform (Hilbert) 


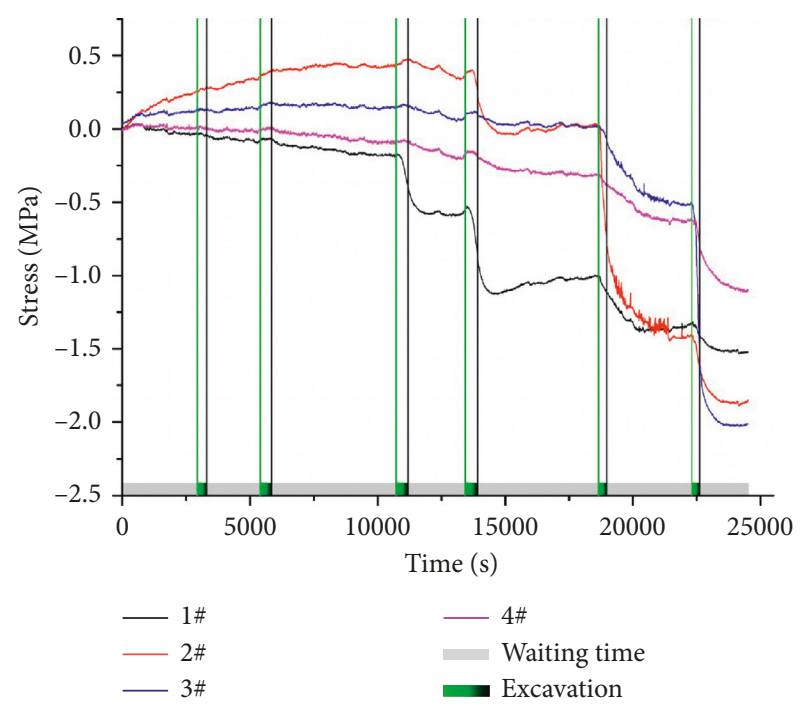

FIGURE 7: Stress evolution diagram during the whole experiment.

with multiresolution and adaptive features. It provides an accurate time resolution for the signal energy-frequency representation. Compared with the Fourier transform, the Hilbert-Huang transform is simple and reliable in studying the microseismic wave before the occurrence of impact ground pressure and can extract MS waveform feature information more completely [34]. At present, the signal processing method has been applied in the fields of earthquake and blast prediction, biomedicine, finance, and geology $[35,36]$.

The basis of the HHT transform is EMD decomposition, also known as signal sorting, which eliminates some of the superimposed waves in the signal. The algorithm flow of EMD decomposition is as follows:

(i) Define the original signal and initialize it: $r_{0}=$ $x(t)$ and $i=1$.

(ii) Calculate the $i$-th IMF component:

(a) Initialization: $h_{0}=r_{i-1}(t)$ and $j=1$.

(b) Find all extreme points in the signal $h_{j-1}(t)$; connect all maxima points and perform cubic spline interpolation to obtain the upper envelope $x_{\max }(t)$; and connect all minima points and perform envelopes under cubic spline interpolation $x_{\min }(t)$.

(c) Calculate the average $m_{j-1}(t)$ of the upper and lower envelopes.

(d) Calculate the decomposed signal: $h_{j}(t)=h_{j-1}(t)-m_{j-1}(t)$.

(e) Determine whether $h_{j}(t)$ is an IMF function, if yes: $\operatorname{imf}_{i}(t)=h_{j}(t)$; otherwise, $j=j+1$.

Then, return step (b) until the calculated $h_{j}(t)$ satisfies the IMF component criteria.

(iii) Calculate the residual component: $r_{i}(t)=r_{i-1}(t)-$ $\operatorname{imf}_{i}(t)$.

(iv) Calculate the number of extreme points of the sequence $r_{i}(t)$; if the number exceeds $2, i=i+1$; otherwise, the decomposition ends, and $r_{i}(t)$ is defined as the residual component. The result of the decomposition is $x(t)=\sum_{i=1}^{n} \operatorname{imf}_{i}(t)+r_{n}(t)$.

The standard deviation between two consecutive processing results is typically used as the judgment calculation standard of the IMF component. When the value of the standard deviation is smaller than a given threshold (generally 0.2 to 0.3 ), the data obtained by the screening are considered to be an IMF component. The decomposed IMF component constitutes a series of signal clusters from high frequency to low frequency. Combining one or more IMF components can obtain the required signal components. The time-domain signal-processing method is based on various IMF components, which can fully preserve the nonstationary characteristics of the original signal.

EMD has good adaptability, but its decomposed signal is prone to the mode-mixing problem. The ensemble empirical mode decomposition (EEMD) based on the EMD method utilizes the uniform distribution of white noise, adds white noise to the original signal, and then performs EMD decomposition, which can effectively overcome the modemixing problem [37].

We used DataDemon software for HHT signal denoising. The software is used to decompose the original signal and then reconstruct the useful signal using the MATH function to obtain the denoised signal. In order to better demonstrate the signal processing process, we selected a $5 \mathrm{~s}$ signal for analysis. The original microseismic signal is shown in Figure 8. After the EEMD decomposition of the original signal, 14 IMF components and one residual component are obtained (shown in Figure 9). Comparing the different IMF component waveforms, it can be found that the noise signal is mainly in the high frequency components (IMF1-IMF5). The IMF6-IMF14 and residual components are reconstructed by the MATH function to obtain the denoised signal shown in Figure 10. Compared with denoised and original signals, it can be found that the HHT method has a good denoising effect on the microseismic signal. The highfrequency noise signal is effectively filtered out when the amplitude of the useful signal does not change much which indicates that the useful signal is sufficiently preserved.

The microseismic signals collected during the experiment are shown in Figure 11. Compared with the signals before and after denoising, the HHT can effectively remove the noise signals that occur during the continuous and stopping excavation. As shown in Figure 11, obvious microseismic signals are generated during excavation and waiting time. However, the signals in these two processes are highly different. The microseismic signals generated by coal destruction during the simulated excavation process are single-pulse signals, and the signals exhibit obvious periodicity. During the experiment, a drilling process was used to simulate the coal excavation, and the vibration of the drilling machine has obvious periodicity, which results in the periodicity of the coal destruction. Comparing Figures 11(b) and 11(f), one can note that the amplitude and pulse number of the microseismic signals that occur during excavation are much larger than those that occur during the waiting time. This phenomenon is primarily due to 


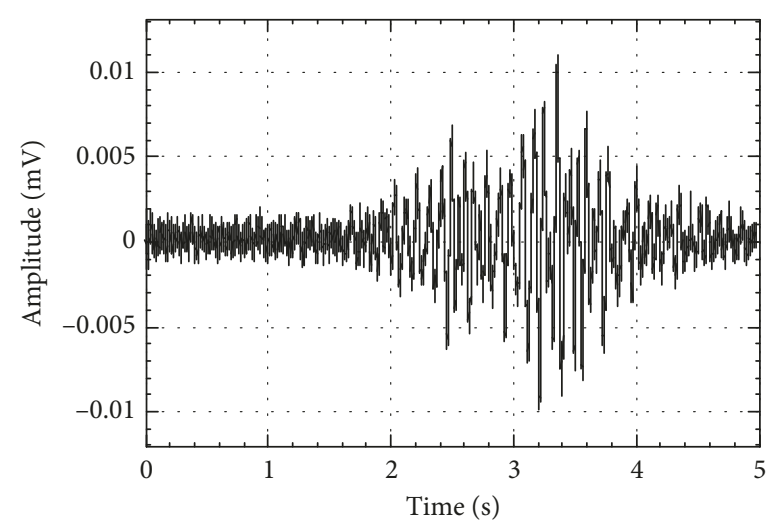

Figure 8: Original microseismic signal.
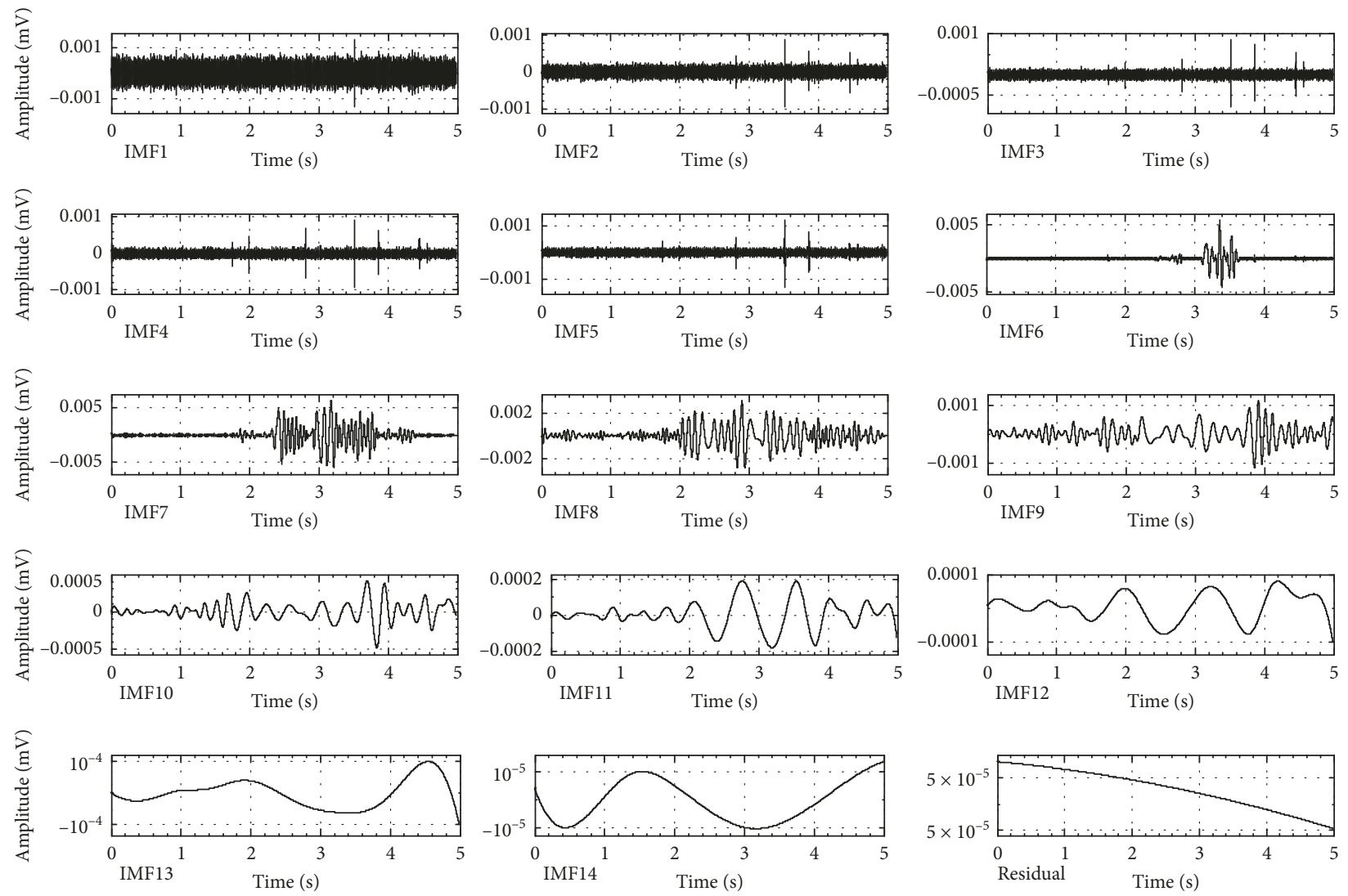

FIgURE 9: IMF components obtained by EEMD.

the severe destruction of the coal seam during the coal roadway excavation, and the released signals are also relatively large. However, the forward movement of the concentrated stress in front of the head face after coal excavation causes the local coal body to be destroyed, which is the main source of the microseismic signal. In this process, the signal amplitude is lower and the number of microseismic pulses is small.

\section{Discussion}

According to the described experimental results, the characteristics of microseismic signals that occur during excavation and those that occur during waiting time are highly different. In the coal mining, how to increase the excavation speed as much as possible while avoiding coal and rock dynamic disasters is a key problem. In this section, the event numbers and energy trends of microseismic signals at different excavation speeds are studied. The STA/LTA algorithm is used to identify the microseismic event and then to calculate the event numbers of the microseismic signal. In the STA/LTA algorithm, first a short window is taken in a given sliding long window, and the starting point or the end point of the two windows coincides. Then, the amplitude change 


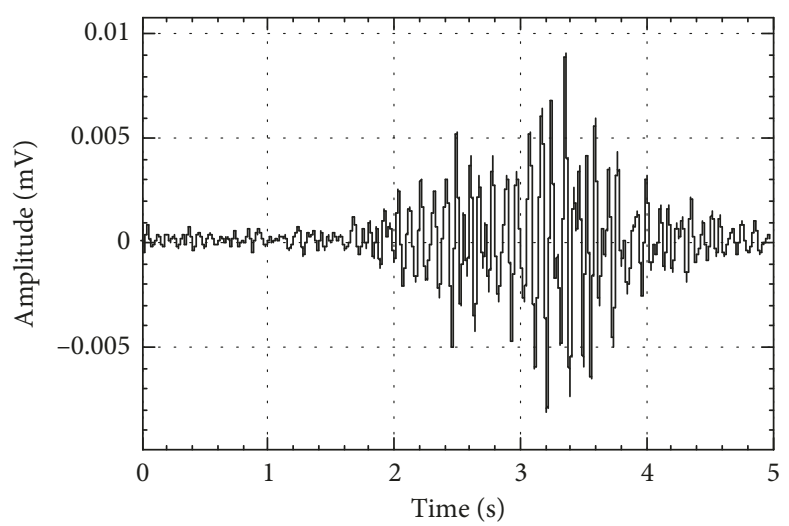

Figure 10: Denoised microseismic signal.

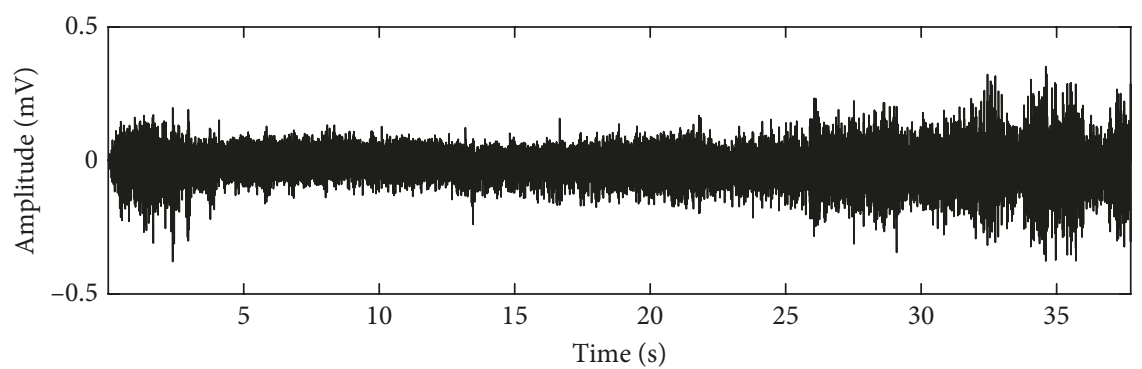

(a)

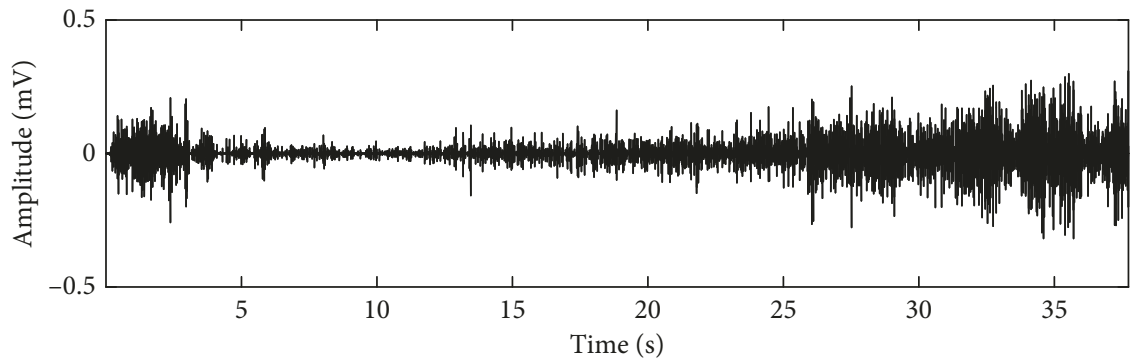

(b)

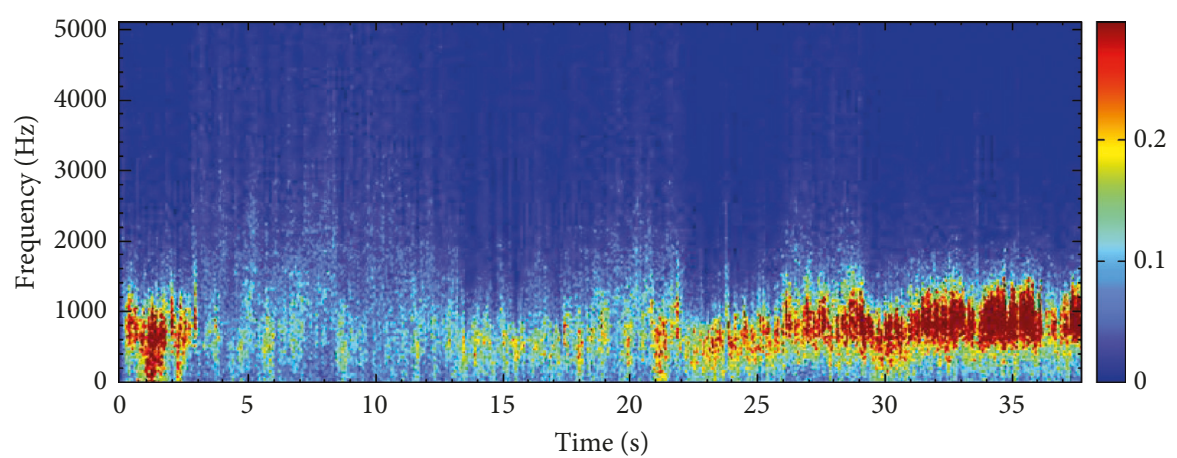

(c)

Figure 11: Continued. 


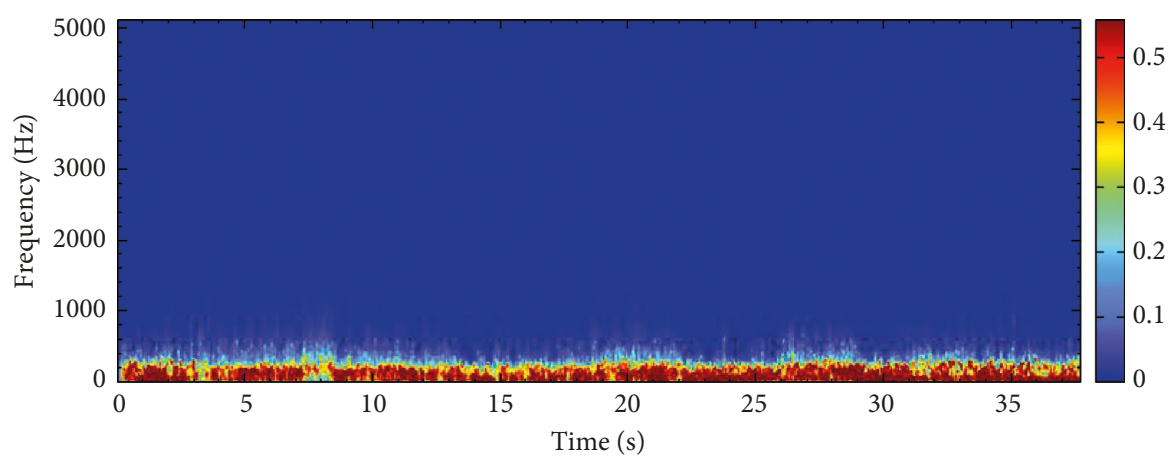

(d)

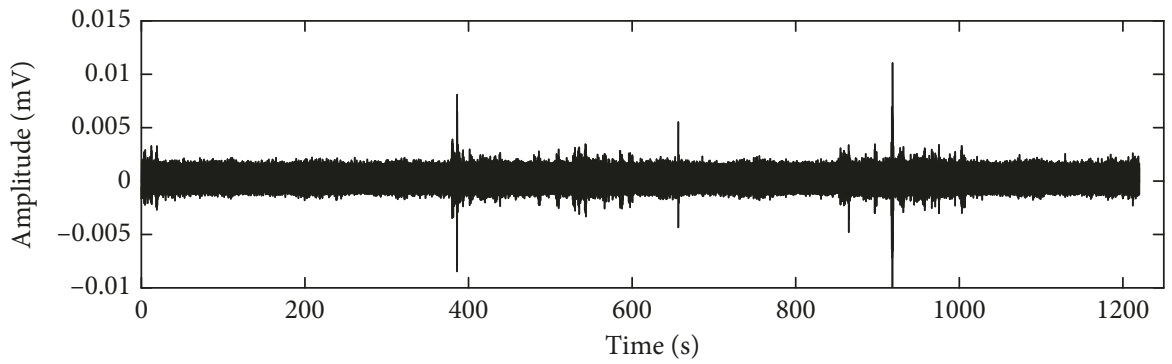

(e)

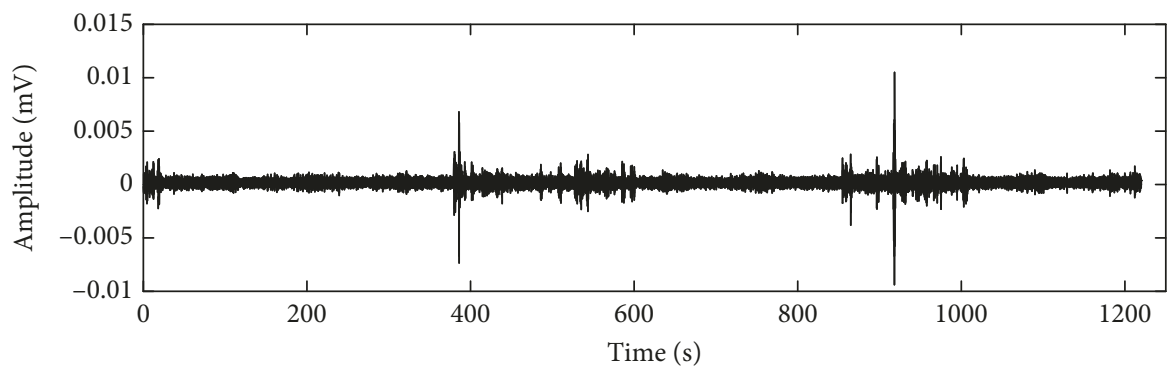

(f)

FIGURE 11: Original microseismic signals and denoised signals collected in the experiment: (a) signal before denoising during excavation; (b) denoised signal during excavation; (c) signal spectrum before denoising during excavation; (d) denoised signal spectrum during excavation; (e) original signal during waiting time; (f) signal after denoising during waiting time.

of the signal is reflected by the ratio $R$ of the short-time average (STA) to long-time average (LTA). STA primarily reflects the characteristics of microseismic signals, while LTA primarily reflects the characteristics of background signals. When $R$ is increased beyond the set threshold, abnormal microseismic signals are considered to be released. Indicator $R$ can be calculated by the following formula:

$$
R=\frac{\mathrm{STA}}{\mathrm{LTA}}=\frac{\sum_{i=1}^{N} X(i) / N}{\sum_{j=1}^{M} X(j) / M},
$$

where $X(i)$ is the eigenfunction values of microseismic signals, which is typically the absolute of the signal amplitude or energy; $N$ is the length of the short window; and $M$ is length of the long window.

To improve signal identification accuracy, a more sensitive signal sequence is constructed, which can respond to the change in amplitude and frequency of the microseismic signal. The eigenfunction $\mathrm{CF}(t)$ of the microseismic signal can be described as follows:

$$
\mathrm{CF}(t)=Y(i)^{2}+K(i)[Y(i)-Y(i-1)]^{2},
$$

where $Y(i)$ is the original amplitude of the signal and $K(i)$ is the weighting factor of the amplitude and first derivative. $K(i)$ can be calculated as follows:

$$
K(i)=\frac{\operatorname{SUM}|Y(i)|}{\operatorname{SUM}|Y(i)-Y(i-1)|} .
$$

In this paper, the $R$ value is corrected by the energy ratio method. The final microseismic signal determination sequence MR can be described as follows:

$$
\operatorname{MR}=\left(\operatorname{abs}(Y(i)) \times R_{i}\right)^{3} .
$$

In the calculation, the length of the SAT window is set to 40 (approximately $3.90 \mathrm{~ms}$ ) and the length of the LAT window is set to 360 (approximately $35.16 \mathrm{~ms}$ ). 

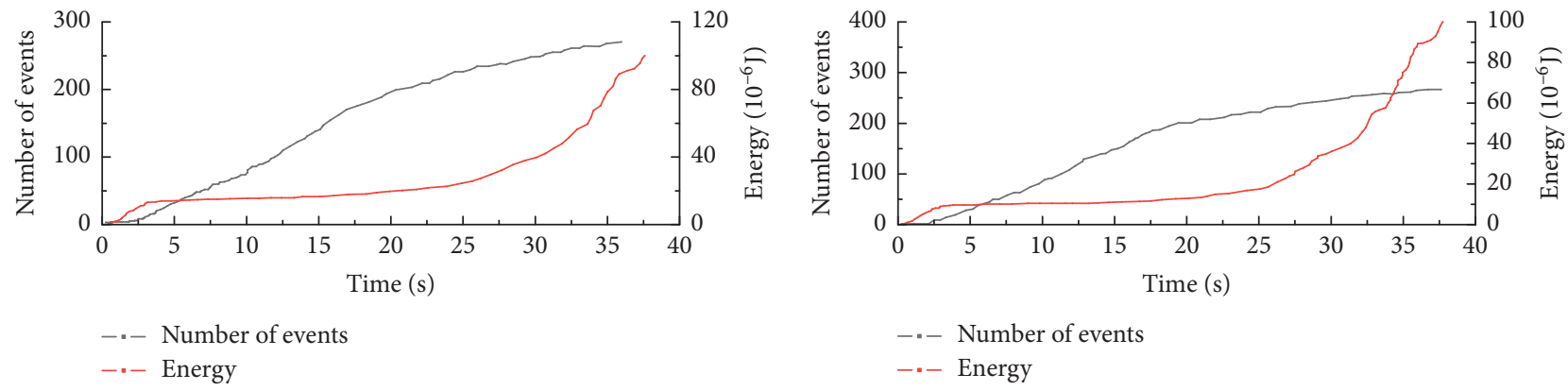

(a)

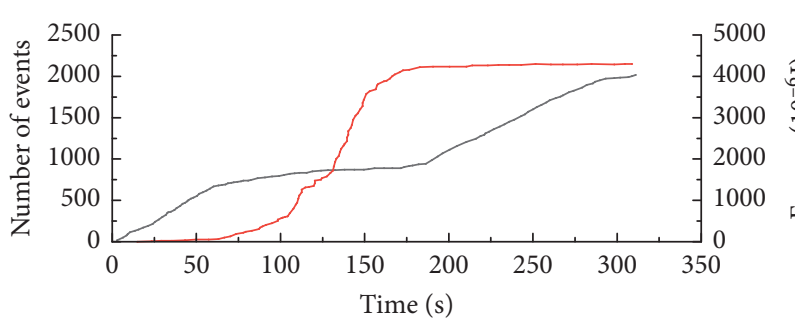

$-\cdot-$ Number of events $-\cdot-$ Energy

(c)

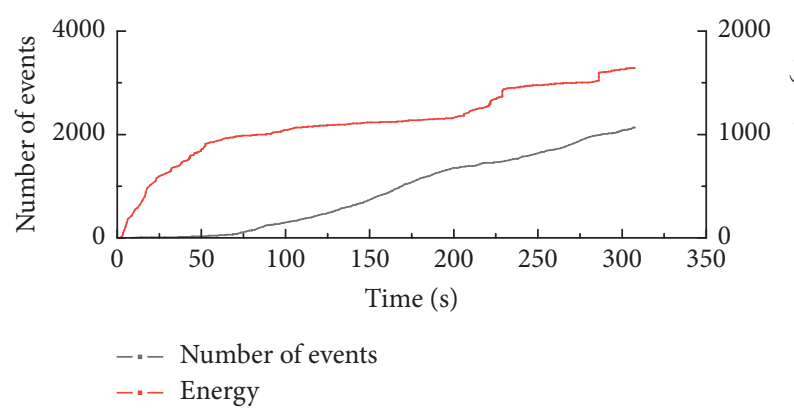

(e) (b)

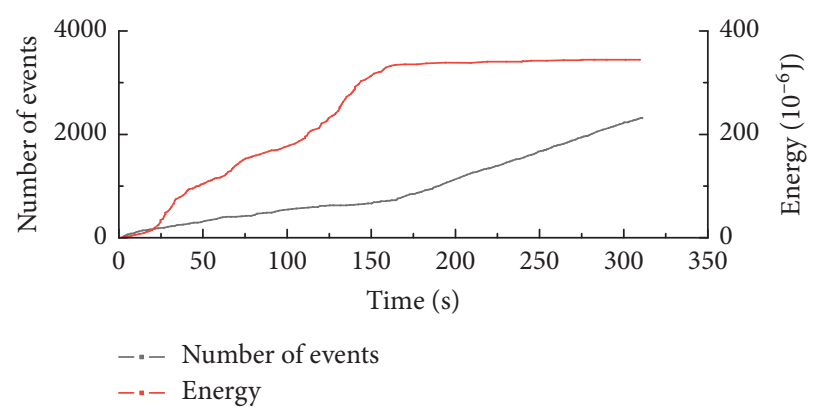

(d)

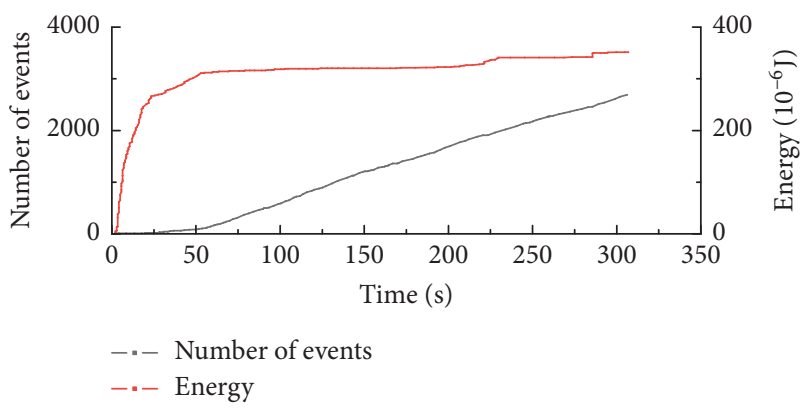

(f)

FiguRE 12: Microseism signal change trend of energy and event numbers at a range of excavation speeds: (a) microseismic sensor 1\# at excavation speed $v_{1}$; (b) microseismic sensor $2 \#$ at excavation speed $v_{1}$; (c) microseismic sensor $1 \#$ at excavation speed $v_{2}$; (d) microseismic sensor $2 \#$ at excavation speed $v_{2}$; (e) microseismic sensor $1 \#$ at excavation speed $v_{3}$; (f) microseismic sensor $2 \#$ at excavation speed $v_{3}$.

The trend of the energy and event numbers of microseismic signals over time at a range of excavation speeds can be obtained by calculation. The calculation results are shown in Figure 12.

As shown in Figure 12, the energy and the event numbers of the microseismic signals exhibit an upward trend. However, the upward curve is very different. The energy of the microseismic signal first increases rapidly and then changes slightly, while the event numbers increase linearly with time. The rapid increase in the microseismic energy in the early stage indicates that the rupture of the coal seam in the experimental cavity gradually increases with the progress of the excavation. However, as the internal stress of the coal seam is removed after the excavation, the energy of the single microseismic pulse is substantially greatly reduced. This leads to a continuous and rapid increase in the number of microseismic events, while the total energy of the microseismic signals changes slowly. Comparing the energy change curves under different excavation speeds reveals that the faster the excavation speed is, the earlier the time of the phase is when the energy of the microseismic signal increases sharply.

Microseismic signal indicators such as energy per second and event numbers per second, during excavation and subsequent waiting time at different excavation speeds, are counted. The calculation results are shown in Table 2.

As shown in Table 2, the energy of the microseismic signal per second increases first and then decreases with the increase in the excavation speed. The event numbers per second at different speeds behave similarly. This is consistent with the previous conclusion that excessive excavation speed does not lead to the larger microseismic energy.

The percentage of time required for the energy of the microseismic signal to reach $90 \%$ of the total time during the excavation process is positively correlated with the excavation speed. With the increase in the excavation speed, the time consumption increases. Comparing the microseismic 
TABle 2: Features of the microseismic signal energy and event numbers.

\begin{tabular}{lcccc}
\hline & \multicolumn{3}{c}{$\begin{array}{c}\text { Excavation speed } \\
\text { during the }\end{array}$} \\
Microseismic signal indicator & \multicolumn{4}{c}{$\begin{array}{c}\text { excavation } \\
\text { operation }\end{array}$} \\
& $v_{1}$ & $v_{2}$ & $v_{3}$ \\
\hline $\begin{array}{l}\text { Energy per second of microseismic pulse } \\
\text { during the excavation (m)/s) }\end{array}$ & 10.86 & 21.30 & 8.37 \\
$\begin{array}{l}\text { Event numbers per second during the } \\
\text { excavation (1/s) }\end{array}$ & 17.15 & 16.14 & 19.73 \\
$\begin{array}{l}\text { Percentage of the total time required for the } \\
\text { energy to reach 90\% during excavation }(\%)\end{array}$ & 54.7 & 82.6 & 87.6 \\
$\begin{array}{l}\text { Total energy during waiting time after } \\
\text { excavation for a period of time (m) }\end{array}$ & 2.42 & 6.25 & 53.34 \\
$\begin{array}{l}\text { Event numbers during waiting time } \\
\text { Energy per second during waiting time } \\
\text { (m)/s) }\end{array}$ & 27.0 & 53.0 & 102.0 \\
\hline
\end{tabular}

signals in the waiting time process after excavation at different speeds reveals that the signal energy and event numbers are greater in the waiting time process after excavation at a faster speed. Specifically, when the driving speed $v_{1}=1.875 \mathrm{~mm} / \mathrm{min}, \quad v_{2}=3.125 \mathrm{~mm} / \mathrm{min}, \quad$ and $v_{3}=4.375 \mathrm{~mm} / \mathrm{min}$, the total energy of the microseismic signal is $2.424 \mathrm{~mJ}, 6.255 \mathrm{~mJ}$, and $53.344 \mathrm{~mJ}$, respectively, and the total number of events is 27,53 , and 102 , respectively. This outcome indicates that when the excavation speed is too fast, the stress distribution of the coal seam does not have enough time to reach equilibrium, and a large amount of unstable deformation energy remain accumulated. When the excavation stops, along with the forward movement of concentrated stress, unstable deformation energy is released, causing the fracture of the coal body and the release of the microseismic signal. The faster the excavation speed is, the stronger the unstable energy is accumulated, and the more the microseismic signal is released during excavation.

During the excavation process, the degree of coal failure in front of the working face does not always increase as the excavation speed increases. The release of the microseismic signal is affected by the excavation speed and the stress advancement speed. When the excavation speed is too fast, the stress at the head will not affect the deeper coal in a short time, and the increase in the coal body damage range is no longer obvious. However, after stopping the excavation (typical for the roadway support process in a coal mine), the stress of the coal seam continues to change drastically, causing large-scale instability and damage to the coal body and triggering a coalrock dynamic disaster. A large number of microseismic signals continue to be released during this process, and the monitoring of these signals can be used for the prediction and early warning of coal and rock dynamic disasters.

\section{Conclusion}

In this paper, a coal roadway excavation simulation experiment system was designed. In addition, the microseismic signals emitted by coal during excavation and by the coal roadway during the subsequent waiting time at different excavation speeds were collected and analyzed. The main conclusions are as follows:

(1) During the excavation and subsequent waiting time, the stress in the coal seam is redistributed, and the concentrated stress is gradually transferred deeper into the coal seam.

(2) The HHT transform could effectively denoise the microseismic signals during the simulated excavation. Compared with the microseismic signals emitted during the waiting time, the microseismic signals emitted during excavation are more densely released and their amplitude is higher. This finding indicates that the stress in front of the working face changes substantially during excavation and that coal is violently destroyed across a wide range.

(3) During the excavation, the energy and event numbers of the microseismic signals first increase and then decrease with the increases in excavation speed.

(4) The faster the excavation speed, the more the energy, and the higher the event numbers of the microseismic signals released during the subsequent waiting time. When the excavation speed is faster, more elastic potential accumulates in the coal seam, and the concentration stress will be greater. As the concentrated stress moves forward in the time without excavation, more coal seams fail, and more microseismic signals are released.

\section{Data Availability}

The data used to support the findings of this study are available from the corresponding author upon request.

\section{Conflicts of Interest}

The authors declare that there are no conflicts of interest regarding the publication of this paper.

\section{Acknowledgments}

This research was financially supported by the Natural Science Foundation of China (Grant nos. 51274206 and 51404277).

\section{References}

[1] A. J. Rorke and C. Roering, "Source mechanism studies of mine-induced seismic events in a deep-level gold mine," International Journal of Rock Mechanics and Mining Sciences and Geomechanics Abstracts, vol. 22, no. 6, p. 198, 1985.

[2] T. LI, M. F. Cai, and M. Cai, "A review of mining-induced seismicity in China," International Journal of Rock Mechanics and Mining Sciences, vol. 44, no. 8, pp. 1149-1171, 2007.

[3] M. Cai, C. D. Kaiser, and C. D. Martin, "Quantification of rock mass damage in underground excavations from microseismic event monitoring," International Journal of Rock Mechanics and Mining Sciences, vol. 38, no. 8, pp. 1135-1145, 2001. 
[4] M. Ge, "Efficient mine microseismic monitoring," International Journal of Coal Geology, vol. 64, no. 1-2, pp. 44-56, 2005.

[5] H. Li, H. Li, B. Gao, D. Jiang, J. Feng, and Q. Wang, "Study of acoustic emission and mechanical characteristics of coal samples under different loading rates," Shock and Vibration, vol. 2015, Article ID 693612, 23 pages, 2015.

[6] J. Fu-Xing, Y. Shu-Hua, C. Yun-Hai et al., "A study on microseismic monitoring of rock burst in coal mine," Chinese Journal of Geophysics, vol. 49, no. 5, pp. 1511-1516, 2006.

[7] W. Blake, F. Leighton, and W. I. Duvall, Microseismic Techniques for Monitoring the Behavior of Rock Structures, Technical Report Archive \& Image Library, Washington, DC, USA, 1974.

[8] X. Luo, A. Creighton, and J. Gough, "Passive seismic monitoring of mine-scale geothermal activity: a trial at Lihir open pit mine," Pure and Applied Geophysics, vol. 167, no. 1-2, pp. 119-129, 2009.

[9] V. A. Mansurov, "Prediction of rockbursts by analysis of induced seismicity data," International Journal of Rock Mechanics and Mining Sciences, vol. 38, no. 6, pp. 893-901, 2001.

[10] S. Wang, C. Li, W. Yan et al., "Multiple indicators prediction method of rock burst based on microseismic monitoring technology," Arabian Journal of Geosciences, vol. 10, no. 6, p. 132, 2017.

[11] Z. Zhang, N. E. Wang, and N. Li, "Temporal and spatial characteristics of coal-mine microseism based on single-link cluster," Geosciences Journal, vol. 21, no. 2, pp. 223-233, 2017.

[12] H. Li, R. Wang, S. Cao, Y. Chen, N. Tian, and X. Chen, "Weak signal detection using multiscale morphology in microseismic monitoring," Journal of Applied Geophysics, vol. 133, pp. 39-49, 2016.

[13] A.-Y. Cao, L.-M. Dou, X. Luo, Y.-D. Zheng, J.-L. Huang, and K. Andrew, "Seismic effort of blasting wave transmitted in coal-rock mass associated with mining operation," Journal of Central South University, vol. 19, no. 9, pp. 2604-2610, 2012.

[14] G. K. Ghosh and C. Sivakumar, "Application of underground microseismic monitoring for ground failure and secure longwall coal mining operation: a case study in an Indian mine," Journal of Applied Geophysics, vol. 150, pp. 21-39, 2018.

[15] W. S. Phillips, L. S. House, M. C. Fehler et al., "Detailed joint structure in a geothermal reservoir from studies of induced microearthquake clusters," Journal of Geophysical Research: Solid Earth, vol. 102, no. B6, pp. 11745-11763, 1997.

[16] C. A. Rowe, R. C. Aster, W. S. Phillips, R. H. Jones, B. Borchers, and M. C. Fehler, "Using automated, highprecision repicking to improve delineation of microseismic structures at the soultz geothermal reservoir," The Mechanism of Induced Seismicity, vol. 159, no. 1-3, pp. 563-596, 2002.

[17] S. J. Gibowicz and S. Lasocki, "Seismicity induced by mining: ten years later," Advances in Geophysics Volume 44, vol. 44, pp. 39-181, 2001.

[18] C. P. Lu, L. M. Dou, B. Liu et al., "Microseismic low-frequency precursor effect of bursting failure of coal and rock," Journal of Applied Geophysics, vol. 79, pp. 55-63, 2012.

[19] M. Sikora, "Induction and pruning of classification rules for prediction of microseismic hazards in coal mines," Expert Systems with Applications, vol. 38, no. 6, pp. 6748-6758, 2011.

[20] J. A. Vallejos and S. D. Mckinnon, "Logistic regression and neural network classification of seismic records," International Journal of Rock Mechanics and Mining Sciences, vol. 62, no. 9, pp. 86-95, 2013.

[21] H. Jiang, Z. Wang, X. Zeng, H. Lü, X. Zhou, and Z. Chen, "Velocity model optimization for surface microseismic monitoring via amplitude stacking," Journal of Applied Geophysics, vol. 135, pp. 317-327, 2016.

[22] R. S. Read, "20 years of excavation response studies at AECL's Underground Research Laboratory," International Journal of Rock Mechanics and Mining Sciences, vol. 41, no. 8, pp. 1251-1275, 2004.

[23] Y. K. Chernov and V. Y. Sokolov, "Correlation of seismic intensity with Fourier acceleration spectra," Physics and Chemistry of the Earth, Part A: Solid Earth and Geodesy, vol. 24, no. 6, pp. 523-528, 1999.

[24] M. C. He, J. L. Miao, and J. L. Feng, "Rock burst process of limestone and its acoustic emission characteristics under truetriaxial unloading conditions," International Journal of Rock Mechanics and Mining Sciences, vol. 47, no. 2, pp. 286-298, 2010.

[25] C. P. Lu, L. M. Dou, B. Liu et al., "Microseismic low-frequency precursor effect of bursting failure of coal and rock," Journal of Applied Geophysics, vol. 79, pp. 55-63, 2012.

[26] C.-P. Lu, L.-M. Dou, N. Zhang et al., "Microseismic frequency-spectrum evolutionary rule of rockburst triggered by roof fall," International Journal of Rock Mechanics and Mining Sciences, vol. 64, pp. 6-16, 2013.

[27] A. Palamides and A. Veloni, Signals and Systems Laboratory with MATLAB, CRC Press, Boca Raton, FL, USA, 2010.

[28] D. L. Donoho, I. M. Johnstone, G. Kerkyacharian, and D. Picard, "Wavelet shrinkage: asymptopia?," Journal of the Royal Statistical Society: Series B (Methodological), vol. 57, no. 2, pp. 301-337, 1995.

[29] J. Morlet, "Wave propagation and sampling theory," Geophysics, vol. 47, 1982.

[30] A. Graps, "An introduction to wavelets," IEEE Computational Science and Engineering, vol. 2, no. 2, pp. 50-61, 1995.

[31] R. E. Learned and A. S. Willsky, "A wavelet packet approach to transient signal classification," Applied and Computational Harmonic Analysis, vol. 2, no. 3, pp. 265-278, 1995.

[32] A. G. Hafez, T. A. Khan, and T. Kohda, Earthquake Onset Detection Using Spectro-Ratio on Multi-Threshold Time-Frequency Sub-Band, Academic Press, Inc., Cambridge, MA, USA, 2009.

[33] H. Jiang, Z. Wang, X. Zeng, H. Lü, X. Zhou, and Z. Chen, "Velocity model optimization for surface microseismic monitoring via amplitude stacking," Journal of Applied Geophysics, vol. 135, pp. 317-327, 2016.

[34] X. Li, Z. Li, E. Wang et al., "Extraction of microseismic waveforms characteristics prior to rock burst using Hilbert-Huang transform," Measurement, vol. 91, pp. 101-113, 2016.

[35] N. Roveri and A. Carcaterra, "Damage detection in structures under traveling loads by Hilbert-Huang transform," $M e$ chanical Systems and Signal Processing, vol. 28, pp. 128-144, 2012.

[36] C. Skeberis, Z. D. Zaharis, T. D. Xenos, S. Spatalas, D. N. Arabelos, and M. E. Contadakis, "Time-frequency analysis of VLF for seismic-ionospheric precursor detection: evaluation of Zhao-atlas-marks and Hilbert-Huang transforms," Physics and Chemistry of the Earth, Parts $A / B / C$, vol. 85-86, pp. 174-184, 2015.

[37] Z. Wu and H. Ne, "Ensemble Empirical Mode Decomposition: a noise-assisted data analysis method," Advances in Adaptive Data Analysis, vol. 1, no. 1, pp. 1-41, 2011. 


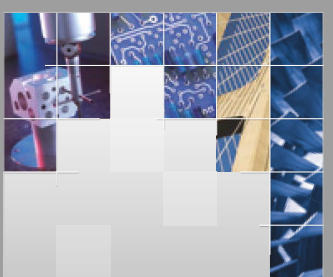

\section{Enfincering}
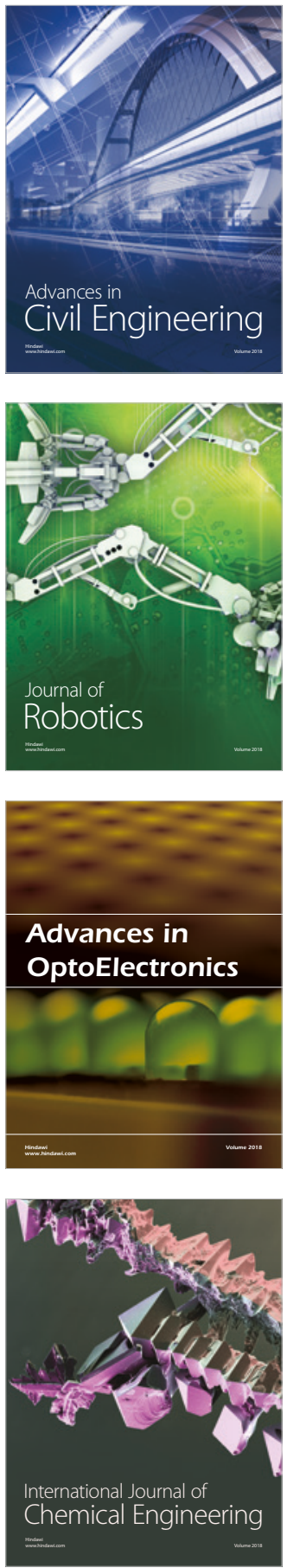

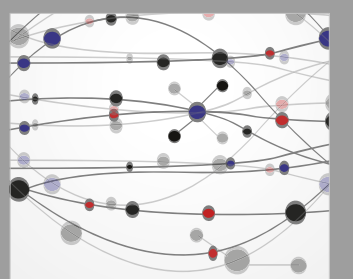

\section{Rotating \\ Machinery}

The Scientific World Journal

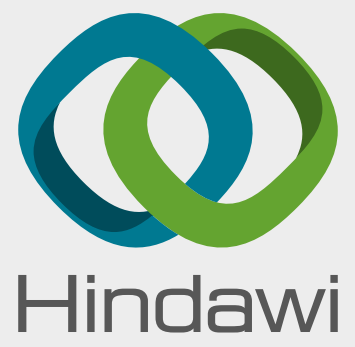

Submit your manuscripts at

www.hindawi.com
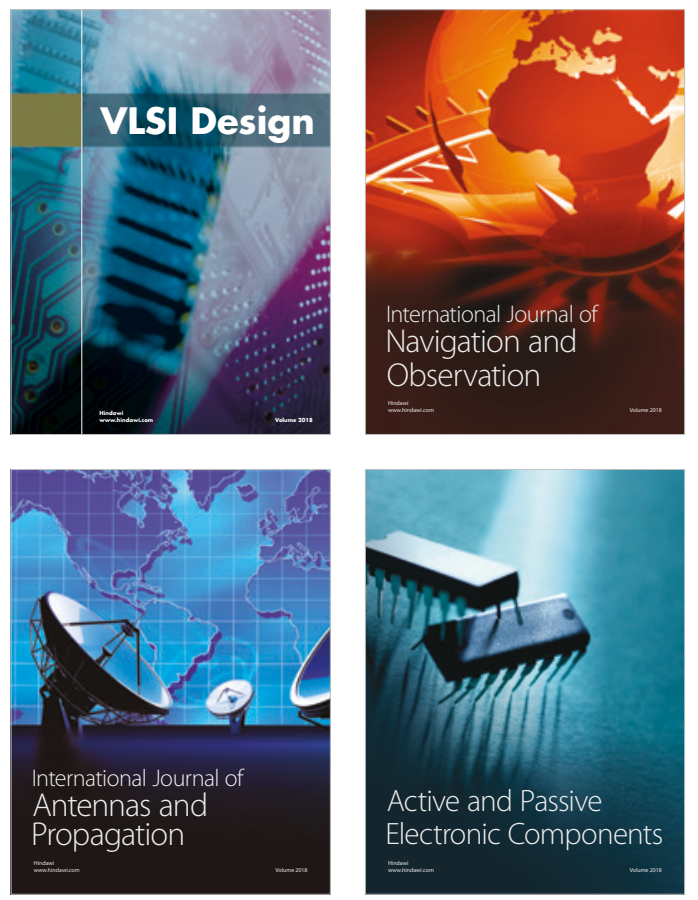
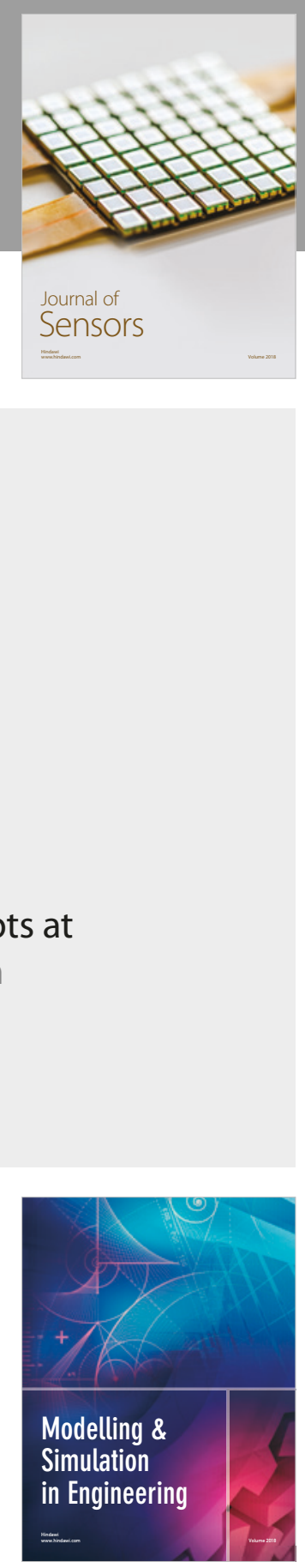

\section{Advances \\ Multimedia}
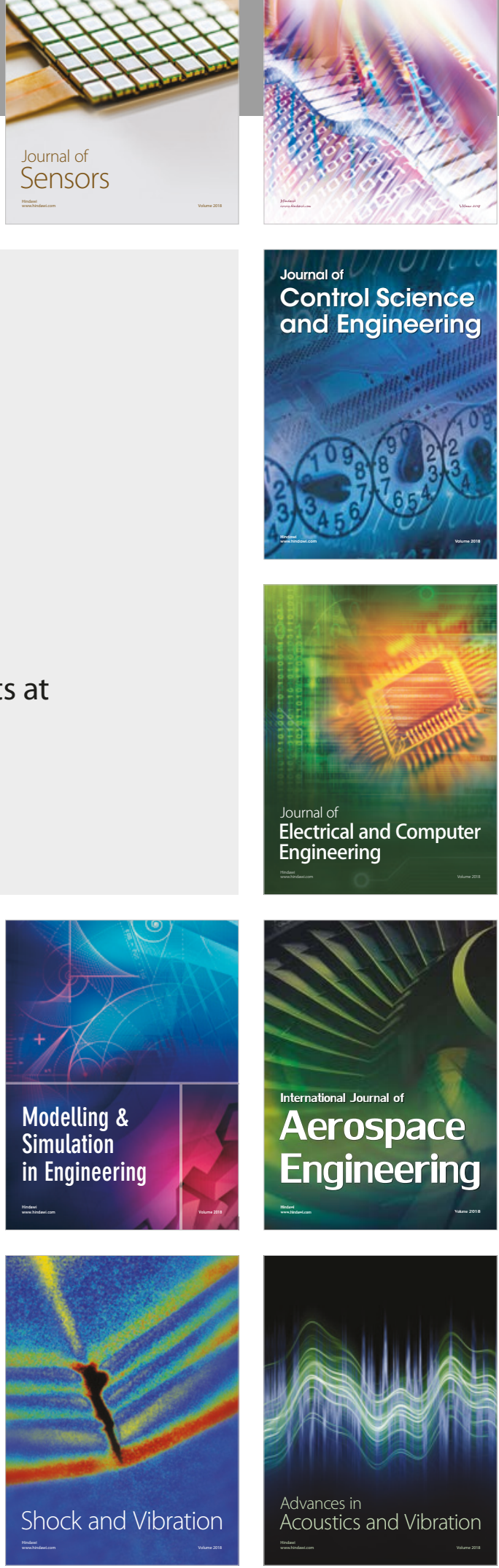